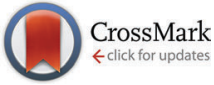

Cite this: Chem. Commun., 2016, 52,10854

Received 28th July 2016, Accepted 5th August 2016

DOI: $10.1039 / \mathrm{c} 6 c c 06095 a$

www.rsc.org/chemcomm

\section{Reductive disproportionation of nitric oxide mediated by low-valent uranium $\uparrow+$}

\author{
Christopher J. Hoerger, ${ }^{a}$ Henry S. La Pierre, ${ }^{\star a b}$ Laurent Maron, ${ }^{c}$ Andreas Scheurer, ${ }^{a}$ \\ Frank W. Heinemann ${ }^{a}$ and Karsten Meyer ${ }^{\star a}$
}

The reductive disproportionation of nitric oxide (1 atm) is mediated by the bulky $U^{\prime \prime \prime}$ aryloxide [U $\left.U^{\text {III }}\left(\mathrm{OAr}{ }^{\mathrm{Ad}, \mathrm{Ad}, \mathrm{Me}}\right)_{3}\right]\left({ }^{\mathrm{Ad}, \mathrm{Ad}, \mathrm{Me}} \mathrm{ArO}=\mathrm{O}-\mathrm{C}_{6} \mathrm{H}_{2}-2,6-\right.$ Ad-4-Me) (1) to form the $U^{\mathrm{V}}$ terminal oxo species $\left[\left({ }^{\mathrm{Ad}, \mathrm{Ad}, \mathrm{Me}} \mathrm{ArO}\right)_{3} \mathrm{U}^{\mathrm{V}}(\mathrm{O})\right]$ (2) and $\mathrm{N}_{2} \mathrm{O}$, as confirmed by single crystal $X$-ray diffraction and GC-MS measurements. The reaction is quantitative in the solid state. Mechanistic and theoretical studies of the reaction suggest that the $\mathrm{N}-\mathrm{N}$ bond is formed by the coupling of an $\eta^{1}-\mathrm{O}$ bound nitric oxide ligand with gaseous $\mathrm{NO}$ to give an $\eta^{1}-\left(\mathrm{N}_{2} \mathrm{O}_{2}\right)^{1-}$ intermediate prior to the spontaneous extrusion of $\mathrm{N}_{2} \mathrm{O}$ to yield the $U^{\mathrm{v}}$ terminal oxo species 2 .

The reactivity of nitric oxide (NO) with transition metal molecular complexes and solid-state materials is a key concern because of the role of NO as biological signaling molecule and its role as a potent greenhouse gas produced as the by-product of hydrocarbon combustion. $^{1-4}$ Initial theoretical studies of the coordination of NO to $\mathrm{U}^{\mathrm{III}}$ complexes suggested that distinct reaction pathways with NO are accessible to uranium and the early actinides, based on their oxophilicity and low-reduction potentials. ${ }^{5}$ In light of both long-standing and recent evidence that uranium can be an efficient catalyst for important small molecule reactions, such as $\mathrm{N}_{2}, \mathrm{CO}_{2}$, and $\mathrm{H}_{2} \mathrm{O}$ reduction, ${ }^{6-12}$ the potential complementary reactivity of uranium with NO may offer unique solutions for NO reduction. However, the investigation of low-valent early actinide reductive disproportionation of NO has been limited by the lack of appropriate coordination chemistry to isolate the reaction products and to identify the relevant redox chemistry of the actinides with NO.

\footnotetext{
${ }^{a}$ Friedrich-Alexander-University of Erlangen-Nürnberg (FAU), Department of Chemistry and Pharmacy, Inorganic Chemistry, Egerlandstrasse 1, 91058 Erlangen, Germany. E-mail: karsten.meyer@fau.de

${ }^{b}$ School of Chemistry and Biochemistry, Georgia Institute of Technology, Atlanta, GA 30332, USA. E-mail: la_pierre@chemistry.gatech.edu

${ }^{c}$ Laboratoire de Physique et Chimie de Nano-objets, UMR 5215 CNRS - Université de Toulouse, 135 avenue de Rangueil, 31077 Toulouse, France

$\dagger$ This paper is dedicated to Professor Helmut Hartung on the occasion of his 80th birthday.

\$ Electronic supplementary information (ESI) available: Synthetic and crystallographic details, NMR spectroscopic, magnetic, computational details, and GC/MS data are included. CCDC 1477612 and 1477613. For ESI and crystallographic data in CIF or other electronic format see DOI: 10.1039/c6cc06095a
}

While Bursten et al. predicted the stability of a N-bound uranium nitrosyl, ${ }^{5}$ Evans and coworkers only recently reported the isolation of a uranium NO complex, namely $\left[\left(\mathrm{C}_{5} \mathrm{Me}_{4} \mathrm{H}\right)_{3} \mathrm{U}(\mathrm{NO})\right]$, featuring a formal $\left(\eta^{1}-\mathrm{NO}\right)^{1-}$ unit with significant interaction between the NO $\pi^{*}$ and the uranium $5 f_{\pi}$ orbitals. ${ }^{13}$ In f-element chemistry, NO gas acts predominantly as an oxygen atom transfer reagent, yielding bridging $\mu$-oxo complexes. ${ }^{6,14,15}$ The mechanism of formation of the $\mu$-oxo and the fate of the NO's nitrogen are unknown. Cloke et al. demonstrated the formation of isocyanate from the $\mathrm{U}^{\mathrm{III}}$ reduction of an equimolar mixture of $\mathrm{CO}$ and NO. DFT calculations suggested the attack of CO onto a $\eta^{2}: \eta^{2}$ bound $\mathrm{NO}$; however, from the direct reaction of NO with $\mathrm{U}^{\mathrm{III}}$ molecular complexes no products could be identified. ${ }^{16,17}$

In order to directly interrogate $\mathrm{U}^{\mathrm{III}}$ reactivity with $\mathrm{NO}$ and to determine the fate of nitrogen in the reaction, a bulky trisaryloxide complex was developed to enforce monometallic reactivity and the formation of mononuclear reaction products. Herein, we report the synthesis of $\left[\mathrm{U}^{\mathrm{III}}\left(\mathrm{OAr}^{\mathrm{Ad}, \mathrm{Ad}, \mathrm{Me}}\right)_{3}\right](\mathbf{1})$ and its reactivity with NO. The bulky, monodentate aryloxide ligand Ad,Ad,Me $\mathrm{ArOK}$ was chosen to protect the reactive, low-coordinate $\mathrm{U}^{\mathrm{III}}$ center, and still be flexible enough to form a cavity for binding and activating NO. The coupling of NO to form $\mathrm{N}_{2} \mathrm{O}$ and $\mathrm{H}_{2} \mathrm{O}$ is a key step in enzymatic systems, such as bacterial nitric oxide reductase (NOR) enzymes and is dependent on exogenous acid $\left(\mathrm{H}^{+}\right){ }^{2,18,19}$ Complex 1 is the first example of an f-element complex to show reductive NO coupling to form $\mathrm{N}_{2} \mathrm{O}$, and it is not dependent on the addition of $\mathrm{H}^{+}$.

The ortho-disubstituted para-cresol, ${ }^{\mathrm{Ad}, \mathrm{Ad}, \mathrm{Me}} \mathrm{ArOH}\left({ }^{\mathrm{Ad}, \mathrm{Ad}, \mathrm{Me}} \mathrm{ArO}=\right.$ O- $\mathrm{C}_{6} \mathrm{H}_{2}$-2,6-Ad-4-Me), is synthesized following a procedure from Kawaguchi et $a l^{20}$ This rigid ligand provides larger steric bulk compared to the sterically encumbered, yet flexible monodentate aryloxide ligand $\left(\mathrm{Ar}^{*} \mathrm{O}\right)^{-}$(with $\left.\mathrm{Ar}^{*}=2,6-\mathrm{Ph}_{2} \mathrm{CH}-\mathrm{C}_{6} \mathrm{H}_{2}-4-\mathrm{Me}\right){ }^{21}$ The corresponding deprotonated salt, ${ }^{\mathrm{Ad}, \mathrm{Ad}, \mathrm{Me}} \mathrm{ArOK}$, is prepared in $94 \%$ yield by addition of $\mathrm{KN}\left(\mathrm{SiMe}_{3}\right)_{2}$ to the phenol in DME suspension. In order to synthesize complex 1 three equivalents of ${ }^{\mathrm{Ad}, \mathrm{Ad}, \mathrm{Me}} \mathrm{ArOK}$ are added to freshly prepared $\mathrm{UI}_{3}$ (dioxane) ${ }_{1.5}{ }^{22}$ After workup, compound $\mathbf{1}$ can be isolated as a red powder in $84 \%$ yield. 
An X-ray diffraction study on single crystals of 1-1.445 $n$-hexane-0.555 $\mathrm{C}_{6} \mathrm{H}_{6}$, grown from slow diffusion of $n$-hexane into a benzene solution of $\mathbf{1}$ at room temperature, reveals that the uranium center lies close to the plane defined by three oxygen atoms of the aryloxide ligand (ESI, $\ddagger$ Fig. S23). Therefore, the geometry can be described as a distorted trigonal plane with the uranium center shifted out of plane (oop) by $0.343 \AA$. This unusual displacement for a three coordinate $\mathrm{U}^{\mathrm{III}}$ ion is rather small in comparison to other complexes with monodentate aryloxide ligands, such as $\left[\mathrm{U}^{\mathrm{III}}(\mathrm{ODtbp})_{3}\right]\left(\right.$ with $(\mathrm{ODtbp})^{-}=$ O- $\left.\mathrm{C}_{6} \mathrm{H}_{3}-2,6-t \mathrm{Bu}\right)$, where the $\mathrm{U}$ ion is shifted $0.81 \AA$ out of the plane of the three phenolate oxygens. ${ }^{23}$ However, this steric enforcement of a near trigonal planar geometry is similar to that observed in $\left[\mathrm{U}^{\mathrm{III}}\left(\mathrm{N}\left(\mathrm{SiMe}_{2} t \mathrm{Bu}\right)_{2}\right)_{3}\right]$, where the uranium center lies almost perfectly in the plane of the ligating nitrogen atoms $\left(U_{\text {oop }}=0.008(2) \AA\right) .{ }^{24}$

Characterization by ${ }^{1} \mathrm{H}$ NMR shows seven characteristic, temperature-independent resonances (ESI, $\ddagger$ Fig. S3). The UV/vis/NIR spectrum shows two bands with $\varepsilon \approx 13000 \mathrm{M}^{-1} \mathrm{~cm}^{-1}$ at 250 and $278 \mathrm{~nm}$, and one absorption at $513 \mathrm{~nm}$ with an extinction coefficient of $1413 \mathrm{M}^{-1} \mathrm{~cm}^{-1}$ (ESI, + Fig. S19 and S20). The spectrum agrees well with that observed for $\left[\mathrm{U}^{\mathrm{III}}(\mathrm{ODtbp})_{3}\right]^{23}$ To further validate the $\mathrm{U}^{\mathrm{III}}$ oxidation state, SQUID magnetization measurements were conducted (ESI, + Fig. S15). The complex exhibits an effective magnetic moment of $\mu_{\text {eff }}=2.96 \mu_{\mathrm{B}}$ at $300 \mathrm{~K}$, which is in the range of other trivalent uranium complexes with monodentate aryloxides, such as $\left[\mathrm{U}^{\mathrm{III}}(\mathrm{ODtbp})_{3}\right]$ with $3.3 \mu_{\mathrm{B}}$ and $\left[\mathrm{U}^{\mathrm{III}}\left(\mathrm{OAr}^{*}\right)_{3}\right]$ with $2.53 \mu_{\mathrm{B}}{ }^{21,23,25}$ It is also in good agreement with other aryloxide complexes from the Meyer group, namely $\left[\left(\left({ }^{t \mathrm{Bu}, t \mathrm{Bu}} \mathrm{ArO}\right)_{3} \mathrm{tacn}\right) \mathrm{U}^{\mathrm{III}}\right]$ (with $\left(\left({ }^{t \mathrm{Bu}, t \mathrm{Bu}} \mathrm{ArO}\right){ }_{3} \text { tacn }\right)^{3-}=$ trianion of 1,4,7-tris-(3,5-di-tert-butyl-2hydroxybenzyl)-1,4,7-triazacyclononane $)$ and $\left[\left(\left({ }^{(\mathrm{Bu}, t \mathrm{Bu}} \mathrm{ArO}\right)_{3} \mathrm{~N}\right) \mathrm{U}^{\mathrm{III}}\right]$ (with $\left(\left({ }^{t \mathrm{Bu}, t \mathrm{Bu}} \mathrm{ArO}\right)_{3} \mathrm{~N}\right)^{3-}=$ trianion of tris(2-hydroxy-3-(1-adamantyl)5 -methylbenzyl)amine) with values of $2.92 \mu_{\mathrm{B}}$ and $3.0 \mu_{\mathrm{B}}$, respectively. ${ }^{25-27}$ Upon cooling to $2 \mathrm{~K}$, the magnetic moment decreases to $1.97 \mu_{\mathrm{B}}$, and is in range with the aforementioned $\mathrm{U}^{\mathrm{III}}$ complexes $\left[\left(\left({ }^{\mathrm{Bu}, t \mathrm{Bu}} \mathrm{ArO}\right)_{3} \mathrm{tacn}\right) \mathrm{U}^{\mathrm{III}}\right]$ with $1.77 \mu_{\mathrm{B}}$ and $\left[\left(\left({ }^{t \mathrm{Bu}, t \mathrm{Bu}} \mathrm{ArO}\right)_{3} \mathrm{~N}\right) \mathrm{U}^{\mathrm{III}}\right]$ with $1.6 \mu_{\mathrm{B}}$. Low-temperature EPR data of trivalent 1 , recorded at $8 \mathrm{~K}$ in toluene, show an asymmetric signal with $g_{\text {eff }}$ values at 3.20, 2.73, and 1.42 (ESI, $\$$ Fig. S18). Calculations with the relation $4 \mu_{\mathrm{eff}}^{2}=\left(g_{1}{ }^{2}+g_{2}{ }^{2}+g_{3}{ }^{2}\right)$ result in a value of $\mu_{\mathrm{eff}}=$ $2.22 \mu_{\mathrm{B}}$, which is in good agreement with the experimentally determined magnetic moment of $\mu_{\text {eff }}=2.13 \mu_{\mathrm{B}}$ at $8 \mathrm{~K}^{28}$

In the solid-state, deep-red trivalent 1 reacts with excess gaseous nitric oxide on contact to form the dark brown terminal oxo species $\left[\left({ }^{\mathrm{Ad}, \mathrm{Ad}, \mathrm{Me}} \mathrm{ArO}\right)_{3} \mathrm{U}^{\mathrm{V}}(\mathrm{O})\right](2)$ as the only product in quantitative yield (Scheme 1). The exclusive formation of nitrous oxide was confirmed by GC-MS measurements (ESI, $\ddagger$ Fig. S7-S10). The formation of $\mathrm{N}_{2}$ was not observed when excess nitric oxide was used. This observation suggests that reduction of NO is substantially faster than $\mathrm{N}_{2} \mathrm{O}$ reduction. $\S$ In contrast, the solid-state reaction of 1 with $\mathrm{N}_{2} \mathrm{O}$ does not lead to complete and clean conversion (ESI, $\neq$ Fig. S6). In benzene solution, complex 2 can be isolated by treatment of 1 with either excess NO (1 atm) in 73\% yield, or with excess $\mathrm{N}_{2} \mathrm{O}(1 \mathrm{~atm})$ in $75 \%$ yield. The reaction of 1 with $\mathrm{N}_{2} \mathrm{O}$ is similar to the one observed for the monomeric

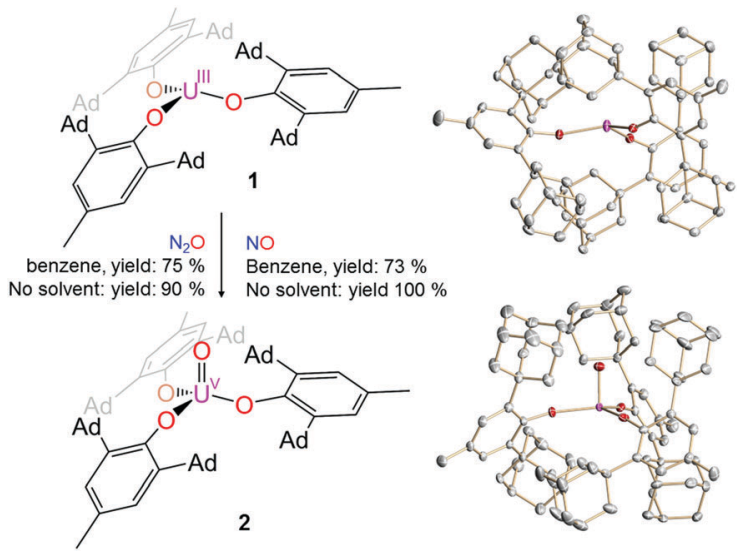

Scheme 1 Reactivity of 1 with $\mathrm{NO} / \mathrm{N}_{2} \mathrm{O}$ yielding 2 (left) and the molecular structures of $\mathbf{1}$ and $\mathbf{2}$ in the solid state (right).

aryloxide complex, $\left[\left(\mathrm{Ar}^{*} \mathrm{O}\right)_{3} \mathrm{U}^{\mathrm{III}}(\mathrm{thf})\right]$, from which the terminal oxo complex $\left[\left(\mathrm{Ar}^{*} \mathrm{O}\right)_{3} \mathrm{U}^{\mathrm{V}}(\mathrm{O})(\mathrm{thf})\right]$ can be isolated. ${ }^{21}$

The molecular structure of 2 , obtained from a single crystal grown from slow diffusion of $n$-hexane into a benzene solution of 2 , confirms that 2 is a monometallic $\mathrm{U}^{\mathrm{V}}$ terminal oxo complex with a trigonal pyramidal coordination geometry (ESI, $¥$ Fig. S24). The uranium center is shifted $0.237 \AA$ out of the plane defined by the oxygen atoms of the aryloxide ligands. The U-O bond length of the terminal oxo moiety is determined to be 1.8175(17) $\AA$; and thus, is in line with other terminal $\mathrm{U}^{\mathrm{V}}$ oxo complexes reported in the literature..$^{21,29,30}$ In UV/vis/NIR spectra, only a single band can be observed in the UV region at $278 \mathrm{~nm}\left(\varepsilon=10500 \mathrm{M}^{-1} \mathrm{~cm}^{-1}\right)$. Only a few distinct absorption bands typical for the oxidation state of $+\mathrm{V}$ for uranium appear to arise from $\mathrm{f}-\mathrm{f}$ transitions in the near infrared region from 900 to $2200 \mathrm{~nm}$ (ESI, $\$$ Fig. S21 and S22). The extinction coefficients vary from 20 to $70 \mathrm{M}^{-1} \mathrm{~cm}^{-1}$.

SQUID magnetization data provides additional evidence for the $\mathrm{U}(\mathrm{v})$ oxidation state (ESI, $\ddagger$ Fig. S16). At $300 \mathrm{~K}, 2$ exhibits an effective magnetic moment of $\mu_{\text {eff }}=2.31 \mu_{\mathrm{B}}$, which is significantly higher than $\mu_{\text {eff }}$ values reported for the terminal oxo complexes $\left[\left(\mathrm{Ar}^{*} \mathrm{O}\right)_{3} \mathrm{U}^{\mathrm{V}}(\mathrm{O})(\mathrm{thf})\right]$ and $\left[\left(\left(\mathrm{Me}_{3} \mathrm{Si}\right)_{2} \mathrm{~N}\right)_{3} \mathrm{U}^{\mathrm{V}}(\mathrm{O})\right]$, with values of 1.96 and $1.59 \mu_{\mathrm{B}}$, respectively. The low-temperature magnetic moment of $0.88 \mu_{\mathrm{B}}$ at $2 \mathrm{~K}$ is in better agreement compared to $0.86 \mu_{\mathrm{B}}$ for $\left[\left(\mathrm{Ar}^{*} \mathrm{O}\right)_{3} \mathrm{U}^{\mathrm{V}}(\mathrm{O})(\right.$ thf $\left.)\right]$ (at $\left.2 \mathrm{~K}\right)$ as well as $0.94 \mu_{\mathrm{B}}$ for $\left[\left(\left(\mathrm{Me}_{3} \mathrm{Si}\right)_{2 \text { - }}\right.\right.$ $\left.\mathrm{N})_{3} \mathrm{U}^{\mathrm{V}}(\mathrm{O})\right]$ (at $\left.4 \mathrm{~K}\right) .^{21,29}$ Pentavalent 2 is EPR active, producing an axial EPR spectrum with $g_{\text {eff }}=2.25$ and 0.71 (ESI, $\ddagger$ Fig. S17). Once again, the calculated $\mu_{\mathrm{eff}}=1.23 \mu_{\mathrm{B}}$ matches well with its experimentally determined low temperature moment of $\mu_{\text {eff }}=1.24 \mu_{\mathrm{B}}$, obtained at $12 \mathrm{~K}$ in toluene solution.

The steric protection afforded by the bulky, monodentate aryloxide enforces the production of a single, monometallic product in the oxidation of $\mathrm{U}^{\mathrm{III}}$ by NO. As stated before, examples for clean reactivity with $\mathrm{NO}$ are rare for f-element complexes and the fate of the nitrogen atom is often not reported. Similarly, after completion of the reaction from 1 to 2 under NO, the nitrogen also cannot be traced to a solid product, as confirmed by elemental analysis. However, GC-MS analysis of the headspace of the reaction mixture confirmed the formation of $\mathrm{N}_{2} \mathrm{O}$. 

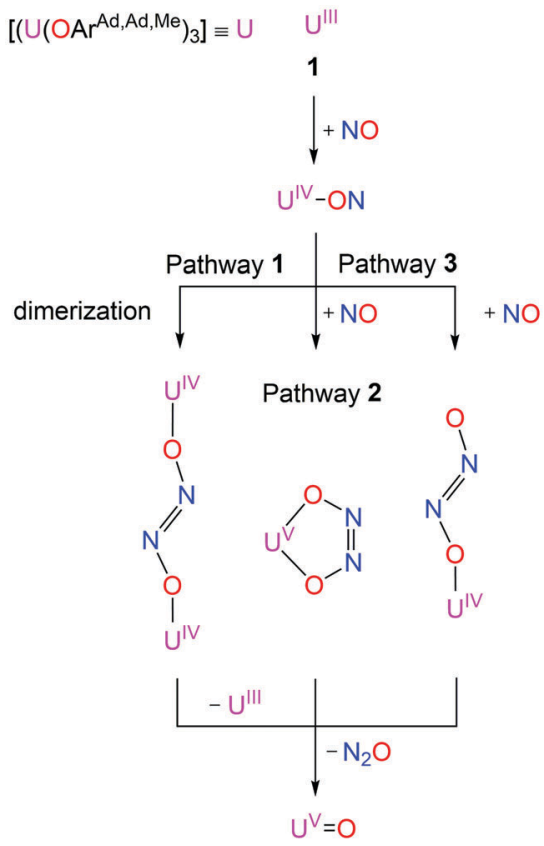

2

Scheme 2 Feasible transition states for the reaction of 1 with nitric oxide.

This observation and the absence of uranium nitride products suggest that a bimetallic NO cleavage reaction, as observed by Cummins and coworkers, was not operative. ${ }^{31}$

The rapid reaction with $\mathrm{NO}$ and exclusive formation of $\mathrm{N}_{2} \mathrm{O}$ in the absence of added $\mathrm{H}^{+}$suggested three possible mechanisms. As shown in Scheme 2 (pathway 1), $\mathrm{N}_{2} \mathrm{O}$ can be formed via an intermediate bimetallic trans-hyponitrite to give 2 and $\mathrm{N}_{2} \mathrm{O}$. Even though it is a reoccurring theme in transition metal chemistry, ${ }^{19,32-34}$ such a possible bimetallic intermediate is unlikely based on the absence of reactivity of complex $\mathbf{1}$ with $\mathrm{CO}$, which is likely due to the steric constraints of the bulky ligand architecture. This absence of reactivity with $\mathrm{CO}$ is in contrast to the reactivity of less sterically encumbered $\mathrm{U}^{\mathrm{III}}$ complexes with $\mathrm{CO},{ }^{23,35-37}$ which form bridging ynediolate complexes, analogous to the proposed trans-hyponitrite intermediate in pathway 1 . No reactivity of 1 with CO is observed; even under elevated temperatures up to $80{ }^{\circ} \mathrm{C}$ and five days reaction time.

Alternatively, two pathways to form 2 are possible, involving the monometallic reductive disproportionation of NO (Scheme 2). After an initial NO binding event, coupling with a second equivalent of NO can result in either a $\kappa^{2}$-cis-hyponitrite intermediate (pathway 2), as has been demonstrated for early metal reduction of $\mathrm{NO}$ to $\mathrm{N}_{2} \mathrm{O},{ }^{38}$ or a trans-hyponitrite intermediate (pathway 3), similar to azide to imide conversion mechanisms observed for group 5 metals. ${ }^{39-41}$ Decomposition of either one of these intermediates would result in the formation of 2 and $\mathrm{N}_{2} \mathrm{O}$.

Due to the rapid reaction and the fleeting nature of intermediates, DFT calculations were undertaken on the full system (no modeling of the adamantyl substituents) to establish a reaction profile (Fig. 1). This binding event is coupled with a redox event with electron transfer from uranium to nitrosyl.

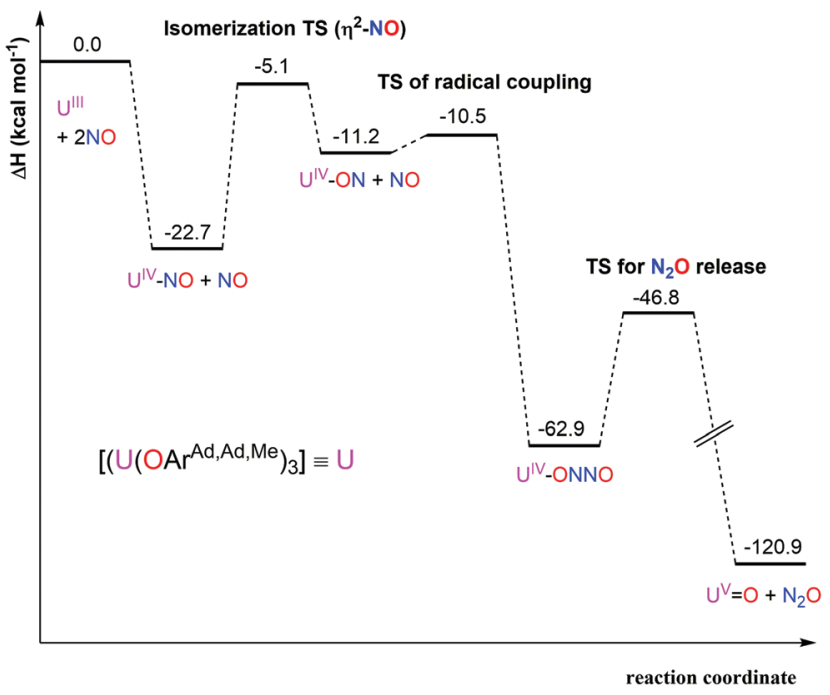

Fig. 1 DFT(B3PW91) computed reaction profile.

Indeed, the two $\mathrm{O}-$ and $\mathrm{N}$-bonded coordination modes are found to be stable minima, with the latter being only $11.5 \mathrm{kcal} \mathrm{mol}{ }^{-1}$ more stable than the former. This result is in accord with the calculations of Bursten et al. and the isolation of a uranium nitrosyl complex by Evans and coworkers. ${ }^{5,13}$ While in our case these nitrosyl intermediates are too fleeting to observe directly, it is informative to note that both the O- and $\mathrm{N}$-bound nitrosyls are bent with a $\mathrm{U}-\mathrm{N}-\mathrm{O}$ and $\mathrm{U}-\mathrm{O}-\mathrm{N}$ angle of $160.9^{\circ}$ and $165.6^{\circ}$, respectively.

However, from the N-bonded adduct, no plausible reaction pathway describing our experimental results was found. This observation indicates that this complex is likely only a resting state for the reaction. From there, it is possible to access the O-bonded adduct via an $\eta^{2}$-NO isomerization transition state. Starting from the O-bonded adduct, a radical coupling with another molecule of NO readily occurs (estimated barrier of $0.7 \mathrm{kcal} \mathrm{mol}^{-1}$ ), yielding a very stable mononuclear hyponitrite complex with a $\mathrm{U}^{\mathrm{IV}}$ center. This complex exhibits an $\eta^{1}$-transhyponitrite rather than a $\kappa^{2}$-cis-coordination (that was not located as a minimum on the potential energy surface (PES)) and the spin density at the uranium center is consistent with a $\mathrm{U}^{\mathrm{IV}}$ rather than a $\mathrm{U}^{\mathrm{V}}$ (two unpaired electrons located at the uranium center in a quartet spin state; depiction of spin density plot in the ESI, + Fig. S25). From this hyponitrite complex, a transition state for the $\mathrm{N}_{2} \mathrm{O}$ release could be located with a low activation barrier of $16.1 \mathrm{kcal} \mathrm{mol}^{-1}$. The analysis of the spin density indicates that the uranium center is already oxidized at the transition state $\left(\mathrm{U}^{\mathrm{V}}\right)$ (the transition state was located on the doublet spin state PES, which is in line with an oxidized uranium center as indicated by the presence of one unpaired spin at the uranium center). This step is thus a single electron transfer (SET) from the uranium center as it induces oxidation from oxidation state $+\mathrm{IV}$ to $+\mathrm{V}$. DFT methods have proven their ability to properly describe SET reactions involving lanthanide and uranium centers. ${ }^{42}$ Finally, this transition state connects the hyponitrite intermediate with the final oxo complex, which 
is strongly stabilized with respect to both complex $\mathbf{1}$ and the hyponitrite species.

In summary, we have prepared the sterically encumbered tris-aryloxide $\mathrm{U}^{\mathrm{III}}$ complex [ $\left.\mathrm{U}^{\mathrm{III}}\left(\mathrm{OAr}^{\mathrm{Ad}, \mathrm{Ad}, \mathrm{Me}}\right)_{3}\right]$ (1) and demonstrated that its reaction with NO leads to the formation of $\left[\left({ }^{\mathrm{Ad}, \mathrm{Ad}, \mathrm{Me}} \mathrm{ArO}\right)_{3} \mathrm{U}^{\mathrm{V}}(\mathrm{O})\right](2)$ and $\mathrm{N}_{2} \mathrm{O}$. DFT calculations suggest that the transformation proceeds through a monometallic $\eta^{1}$-transhyponitrite intermediate, formed through the coupling of exogenous NO with a thermally accessible O-bound nitrosyl ligand. This mechanism is unique to uranium. These results also indicate that, due to the strong reduction potential and oxophilicity of $\mathrm{U}^{\mathrm{III}}$, reaction mechanisms for the reduction of NO can diverge dramatically from those typically observed for first row transition metals. With the renewed interest in uranium small molecule catalysis, ${ }^{11}$ the results on divergent mechanistic pathways accessible to uranium suggest that catalytic reactivity, complementary to transition metal catalysis, can be developed. Finally, considering the similarities between uranium and some transition metal ions, such as iron, with regard to the reducing strength of the low oxidation states and the oxophilicity of the high-valent ion, the presented disproportionation pathway might also be relevant for low-valent transition metal systems, where steric constraint can prevent bimolecular reactions.

This work was supported by funds of the German Federal Ministry of Education and Research (BMBF 2020+ support codes 02NUK012C and 02NUK020C), the Joint DFG-ANR projects (ME1754/7-1, ANR-14-CE35-0004-01) as well as the FAU. We thank Isabell Kenkel and Julia Stuber for assistance with the GC/MS measurements.

\section{Notes and references}

$\S$ Direct measurement of reaction rates is not possible given the extremely fast rates in solution and solid-state. Based on previous attempts to measure $\mathrm{NO}$ and $\mathrm{N}_{2} \mathrm{O}$ reduction by low-valent early metals (see ref. 38) the rates of these reactions are mass transport limited.

1 K. K. Pandey, Coord. Chem. Rev., 1983, 51, 69-98.

2 M. P. Schopfer, J. Wang and K. D. Karlin, Inorg. Chem., 2010, 49, 6267-6282.

3 G. B. Richter-Addo, P. Legzdins and J. Burstyn, Chem. Rev., 2002, 102, 857-859.

4 J. A. McCleverty, Chem. Rev., 2004, 104, 403-418.

5 B. E. Bursten, L. F. Rhodes and R. J. Strittmatter, J. Am. Chem. Soc., 1989, 111, 2758-2766.

6 H. S. La Pierre and K. Meyer, Prog. Inorg. Chem., 2014, 58, 303-415.

7 B. M. Gardner and S. T. Liddle, Eur. J. Inorg. Chem., 2013, 3753-3770.

8 A. R. Fox, S. C. Bart, K. Meyer and C. C. Cummins, Nature, 2008, 455, 341-349.

9 P. L. Arnold, Chem. Commun., 2011, 47, 9005-9010.

10 S. T. Liddle, Angew. Chem., Int. Ed., 2015, 54, 8604-8641.
11 D. P. Halter, F. W. Heinemann, J. Bachmann and K. Meyer, Nature, 2016, 530, 317-321.

12 M. Ephritikhine, Dalton Trans., 2006, 2501-2516.

13 N. A. Siladke, K. R. Meihaus, J. W. Ziller, M. Fang, F. Furche, J. R. Long and W. J. Evans, J. Am. Chem. Soc., 2012, 134, 1243-1249.

14 W. J. Evans, J. W. Grate, I. Bloom, W. E. Hunter and J. L. Atwood, J. Am. Chem. Soc., 1985, 107, 405-409.

15 L. R. Avens, D. M. Barnhart, C. J. Burns, S. D. McKee and W. H. Smith, Inorg. Chem., 1994, 33, 4245-4254.

16 C. E. Kefalidis, A. S. P. Frey, S. M. Roe, F. G. N. Cloke and L. Maron, Dalton Trans., 2014, 43, 11202-11208.

17 A. S. P. Frey, F. G. N. Cloke, M. P. Coles and P. B. Hitchcock, Chem. - Eur. J., 2010, 16, 9446-9448.

18 Y. Shiro, Biochim. Biophys. Acta, 2012, 1817, 1907-1913.

19 Y. Arikawa and M. Onishi, Coord. Chem. Rev., 2012, 256, 468-478.

20 T. Watanabe, Y. Ishida, T. Matsuo and H. Kawaguchi, Dalton Trans., 2010, 39, 484-491.

21 S. M. Franke, B. L. Tran, F. W. Heinemann, W. Hieringer, D. J. Mindiola and K. Meyer, Inorg. Chem., 2013, 52, 10552-10558.

22 M. J. Monreal, R. K. Thomson, T. Cantat, N. E. Travia, B. L. Scott and J. L. Kiplinger, Organometallics, 2011, 30, 2031-2038.

23 S. M. Mansell, N. Kaltsoyannis and P. L. Arnold, J. Am. Chem. Soc., 2011, 133, 9036-9051.

24 C. A. P. Goodwin, F. Tuna, E. J. L. McInnes, S. T. Liddle, J. McMaster, I. J. Vitorica-Yrezabal and D. P. Mills, Chem. - Eur. J., 2014, 20, 14579-14583.

25 D. R. Kindra and W. J. Evans, Chem. Rev., 2014, 114, 8865-8882.

26 O. P. Lam, S. C. Bart, H. Kameo, F. W. Heinemann and K. Meyer, Chem. Commun., 2010, 46, 3137-3139.

27 I. Castro-Rodriguez, K. Olsen, P. Gantzel and K. Meyer, Chem. Commun., 2002, 2764-2765.

28 A.-C. Schmidt, F. W. Heinemann, W. W. Lukens and K. Meyer, J. Am. Chem. Soc., 2014, 136, 11980-11993.

29 S. Fortier, J. L. Brown, N. Kaltsoyannis, G. Wu and T. W. Hayton, Inorg. Chem., 2012, 51, 1625-1633.

30 S. C. Bart, C. Anthon, F. W. Heinemann, E. Bill, N. M. Edelstein and K. Meyer, J. Am. Chem. Soc., 2008, 130, 12536-12546.

31 C. E. Laplaza, A. L. Odom, W. M. Davis, C. C. Cummins and J. D. Protasiewicz, J. Am. Chem. Soc., 1995, 117, 4999-5000.

32 A. M. Wright and T. W. Hayton, Inorg. Chem., 2015, 54, 9330-9341.

33 A. M. Wright, G. Wu and T. W. Hayton, J. Am. Chem. Soc., 2012, 134, 9930-9933.

34 A. M. Wright, H. T. Zaman, G. Wu and T. W. Hayton, Inorg. Chem., 2014, 53, 3108-3116.

35 P. L. Arnold, Z. R. Turner, R. M. Bellabarba and R. P. Tooze, Chem. Sci., 2011, 2, 77-79.

36 A. S. Frey, F. G. N. Cloke, P. B. Hitchcock, I. J. Day, J. C. Green and G. Aitken, J. Am. Chem. Soc., 2008, 130, 13816-13817.

37 B. M. Gardner, J. C. Stewart, A. L. Davis, J. McMaster, W. Lewis, A. J. Blake and S. T. Liddle, Proc. Natl. Acad. Sci. U. S. A., 2012, 109, 9265-9270.

38 K. McNeill and R. G. Bergman, J. Am. Chem. Soc., 1999, 121, $8260-8269$.

39 G. Proulx and R. G. Bergman, J. Am. Chem. Soc., 1995, 117, 6382-6383.

40 G. Proulx and R. G. Bergman, Organometallics, 1996, 15, 684-692.

41 M. G. Fickes, W. M. Davis and C. C. Cummins, J. Am. Chem. Soc., 1995, 117, 6384-6385.

42 C. E. Kefalidis, L. Castro, L. Perrin, I. Del Rosal and L. Maron, Chem. Soc. Rev., 2016, 45, 2516-2543. 